\title{
Periventricular destabilization and ventriculomegaly in aging rats: implications for reduced neurogenesis and cognition
}

\author{
Conrad Johanson*, Arthur Messier, Miles Miller, Crissey Pascale, \\ Kumar Vasudevan, John Donahue, Edward Stopa, Ed Sabo, \\ Ilias Caralopoulos, Petra Klinge, Thomas Brinker and Gerald Silverberg
}

\author{
Address: Department of Neurosurgery, Alpert Medical School at Brown University, Rhode Island Hospital, 593 Eddy Street, Providence, Rhode \\ Island, 02903, USA \\ Email: Conrad Johanson* - Conrad_Johanson@brown.edu \\ * Corresponding author
}

from 53rd Annual Meeting of the Society for Research into Hydrocephalus and Spina Bifida

Belfast, UK. 24-27 June 2009

Published: 27 November 2009

Cerebrospinal Fluid Research 2009, 6(Suppl 2):SI6 doi:10.1186/I743-8454-6-S2-SI6

This abstract is available from: http://www.cerebrospinalfluidresearch.com/content/6/S2/S16

(c) 2009 Johanson et al; licensee BioMed Central Ltd.

\begin{abstract}
Background
Cognitive deficits in aging, NPH and Alzheimer's disease (AD) are exacerbated by compromised neurogenesis in the dentate gyrus (DG) and subventricular zone (SVZ). We previously found beta-amyloid $(A \beta)$ retention in cortex and hippocampus of aged rats and diseased humans, due to greater RAGE and lesser LRP-1 expression of microvascular transporters for $A \beta$. Now we focus on the periventricular DG and SVZ that harbor stem cells convertible to new neurons in adults. Working hypothesis: $A \beta$ retention in neurogenic zones harms neural stem cells, leading to reduced cognition.
\end{abstract}

\section{Materials and methods}

Brown-Norway/Fischer (B-N/F) rats (3, 12, 20 \& $30 \mathrm{mo})$ were tested in a Morris water maze (following placement at 3 starting points along the periphery of a circular water tank) for the time to reach/climb a platform above water. In trials 1-15, we determined the latency (sec) required for rats to mount the platform following placement at the starting point. For trials 1-6, the platform was visible, while trials 6-15 involved the new challenge of finding the submerged platform in the same location. On the final day (probe trial), time spent in quadrant 4 (former location of platform) was measured in the platform absence. Latency was thus used to evaluate the extent of spatial memory recall. Animals were then injected with BrdU (50 $\mathrm{mg} / \mathrm{kg}$ i.p. for $1 \mathrm{hr}$ ) and euthanized with pentobarbital to enable brain sampling for immunohistochemistry (IHC) and microscopy. Univariate statistics on latency for the cued (platform visible) and non-cued (platform hidden) trial hypotheses were done by J. Machan.

\section{Results}

There were significantly different (Holm-Bonferroni adjusted) slopes of mean log (latency) among age groups for several non-cued trials $[p<0.05$ (103 df), 3 vs. $12 ; 12$ vs. $30 ; 20$ vs. $30 \mathrm{mo}$. This then points to progressive decrement, with advancing age, in spatial working memory in B-N/F rats. In DG and SVZ, there was increasing amyloid burden (A $\beta$ 42) and decreasing BrdU (mitosis) activity between 3 \& 30 mo. Astroglial GFAP increased significantly between 12 \& 20 mo, whereas microglial OX6 IHC was enhanced over 20 to $30 \mathrm{mo}$. Staining of nestin (neural stem cell marker) peaked at $20 \mathrm{mo}$, but was reduced at 30 mo. Ependyma dismantling and ventricle enlargement occurred at 30 mo.

\section{Conclusion}

Aged rat CNS at 30 mo resembles NPH/AD. DG \& SVZ are stressed by $\mathrm{A} \beta$ burden and inflammation. The diminished spatial memory prompts potential CSF agent usage to stabilize neurogenesis. 


\section{Acknowledgements}

Supported by NIH ROI AG0279I0 and the Richter and Saunders Funds.

Publish with Biomed Central and every scientist can read your work free of charge

"BioMed Central will be the most significant development for disseminating the results of biomedical research in our lifetime." Sir Paul Nurse, Cancer Research UK

Your research papers will be:

- available free of charge to the entire biomedical community

- peer reviewed and published immediately upon acceptance

- cited in PubMed and archived on PubMed Central

- yours - you keep the copyright 